http://dx.doi.org/10.1590/0370-44672015700065

\author{
Sergio Pastor Ontiveros-Pérez \\ Doutorando \\ Universidade Federal do Rio Grande do Sul - UFRGS \\ Departamento de Engenharia Mecânica \\ Porto Alegre - Rio Grande do Sul - Brasil \\ sergio.ontiveros@ufrgs.br \\ Letícia Fleck Fadel Miguel \\ Professora - Doutora \\ Universidade Federal do Rio Grande do Sul - UFGRS \\ Departamento de Engenharia Mecânica \\ Porto Alegre - Rio Grande do Sul - Brasil \\ letffm@ufrgs.br, letffm@gmail.com \\ Leandro Fleck Fadel Miguel \\ Professor - Doutor \\ Universidade Federal de Santa Catarina - UFSC \\ Departamento de Engenharia Civil \\ Florianópolis - Santa Catarina - Brasil \\ leandro.miguel@ufsc.br
}

\section{Civil Engineering Optimization of location and forces of friction dampers}

\begin{abstract}
Damper optimization is a new area which has been investigated in recent years. There are various methods employed in optimization, among which are highlighted the classic and the most recent that are functioning with reliability, efficiency and speed for optimum results. This paper proposes a method for simultaneous optimization of placement and forces of friction dampers using the Firefly Algorithm, which is a recent meta-heuristic algorithm inspired in the behavior of fireflies.

Herein, three different optimization objective are presented: i) minimize the maximum displacement at the top of the structure; ii) minimize the maximum interstory drift; iii) minimize the maximum acceleration at the top of the structure. The three objective functions were evaluated in two civil structures (a nine-story building and a sixteen-story building) subjected to two real seismic records. The first seismic record is El Centro, which took place in the southeastern California on the boarder of the United States and Mexico in 1940. The second one is the earthquake that occurred in Caucete, province of San Juan, Argentina, in 1977. The results showed that the proposed method was able to optimize the friction dampers, reducing considerably the response of the structures.
\end{abstract}

Keywords: damper optimization, friction dampers, Firefly Algorithm.

\section{Introduction}

The effect of vibrations in buildings caused by dynamic loads such as earthquakes have been the focus of study by several researches as well as the methods used for energy dissipation avoiding structural damage. Energy dissipation in structures is possible through damping device implementation. These devices can be active or passive and their application depends on the investment for the project. Because of their characteristics, passive devices stand out among energy dissipation systems, increasing the development of several of these devices, such as, viscoelastic dampers, metallic yield dampers and friction dampers (Soong and Dargush, 1997).

Recently, several researchers have been working in the optimization of the

\section{Problem formulation}

\subsection{Equation of motion}

The dynamic behavior of a multi- location of the dampers in structures and their parameters. In this way, it is possible to find many papers about the optimization of passive dampers in literature (e.g., Fang et al. (2012) and Takewaki et al. (2012)). With the aim to allow an economic use of friction dampers, several authors have developed methodologies for the optimization of friction dampers in civil structures and their research can be found in literature (e.g, Ontiveros-Pérez (2014); Miguel et al. (2015); Miguel et al. (2016a) Miguel et al. (2016b)).

However few studies have been conducted on the simultaneous optimization of locations and friction forces of friction dampers. Metaheuristic algorithms are able to deal with this kind of optimization problem. Some of the salient characteristics of these kinds of algorithms are: (a) they do not require gradient information; (b) if the metaheuristic algorithm is correctly tuned, it does not become trapped in local minima; (c) it is possible to apply in problems with discontinuous functions; (d) they provide a set of optimal solutions rather than a single one, giving to the designer a range of options to choose from; (e) it is possible to use to solve mixed-variable optimization problems (Miguel et al., 2012, 2013). Thus, note that the optimization of friction dampers is a relatively unexplored subject in the world, and this paper proposes a method for optimization of this kind of passive energy dissipation device.

$$
M \ddot{x}+C \ddot{x}+K x=F_{e x}-F_{f n}
$$

degree of freedom (MDOF) system with friction dampers and subjected to external 
force is represented in Equation 1, where $\boldsymbol{M}$ and $\boldsymbol{K}$ are the $\mathrm{n} \times \mathrm{n}$ size structural mass and stiffness matrices respectively and $\mathrm{n}$ is the degree of freedom number. The damping matrix $\boldsymbol{C}$ is proportional to the $\boldsymbol{M}$ and $\boldsymbol{K}$ matrices. The $\mathrm{n}$-dimensional vector $\boldsymbol{x}$ represents the relative displacement with respect to the base, and the differentiation with respect to the time is represented

It is important to note that the magnitude of the friction force is constant but its direction is always opposite to the sliding velocity. The changes in the direction of the velocity cause discontinuities in the friction force, leading to difficulties to evaluate the response of a system with friction dampers. For this reason, herein is implemented one of four

\subsection{Friction damper operation}

This device uses the solid friction mechanism to give the desired energy dissipation in order to reduce the amplitude of the vibration system. The friction developed between two solid bodies sliding in relation to one another inside the friction damper allows the energy dissipation in a civil structure subjected to an earthquake.

Herein, the numerical scheme of with a dot over the displacement vector symbol. The external force and the Coulomb friction force are represented by the $n$ -dimensional vector $\boldsymbol{F}_{\boldsymbol{e x}}$ and $\boldsymbol{F}_{f_{n}}$ respectively. $\boldsymbol{F}_{e x}=-\boldsymbol{M B} \ddot{\boldsymbol{x}}$, where $\boldsymbol{B}$ is a $\mathrm{n} \times \mathrm{d}$ matrix that contains the cosine directors of the angles formed between the base motion and the direction of the displacement considered degree of freedom (DOF). $d$ is the number

$$
\boldsymbol{F}_{f n}=\mu N \operatorname{sgn}(\vec{v}(t))
$$

continuous functions proposed by Mostaghel and Davis (1997) that represents the discontinuity of the Coulomb friction force. Each one of these functions uses a $\left(\alpha_{i}\right)$ parameter which controls the level of accuracy of the function representing the friction force. The continuous function used in this paper is the function $f_{2}\left(\alpha_{2} v\right)=\tanh \left(\alpha_{2} v\right)$ with $\alpha_{2}=1000$, as

the friction damper Model A proposed by Miguel (2002) (see Figure 1 b)) is used. This damper used brass as material to generate friction and consequently energy dissipation. Thus, the control of normal force at the contact between the brasses is given by two compression springs. This model can be applied in structures subjected to any type of dy- of directions of the ground motion and $\ddot{\boldsymbol{x}}_{g}$ is the d-dimensional ground acceleration vector of the seismic excitation.

Coulomb friction force is represented by Equation (2) where $\mu$ is the friction coefficient (assumed as constant), $N$ is the normal force vector, $\operatorname{sgn}()$ is the signal function and $v(\mathrm{t})$ is the relative velocity vector between the ends of the damper.

already used in previous studies, as Miguel et al. (2008), Miguel et al. (2014), Ontiveros-Pérez (2014)).

A computational routine based on the finite differences method was developed in MATLAB to solve the Equation 1 , determining the dynamic response in terms of displacement of a system with friction dampers.

namic load, such as earthquakes, both in metallic structures and in concrete structures. It may be placed as diagonal bracing bars, as shown in the diagram of Figure 1 a). In addition, if the reader requires more information about the friction damper Model-A, the authors recommended read the Master dissertation of Miguel (2002).

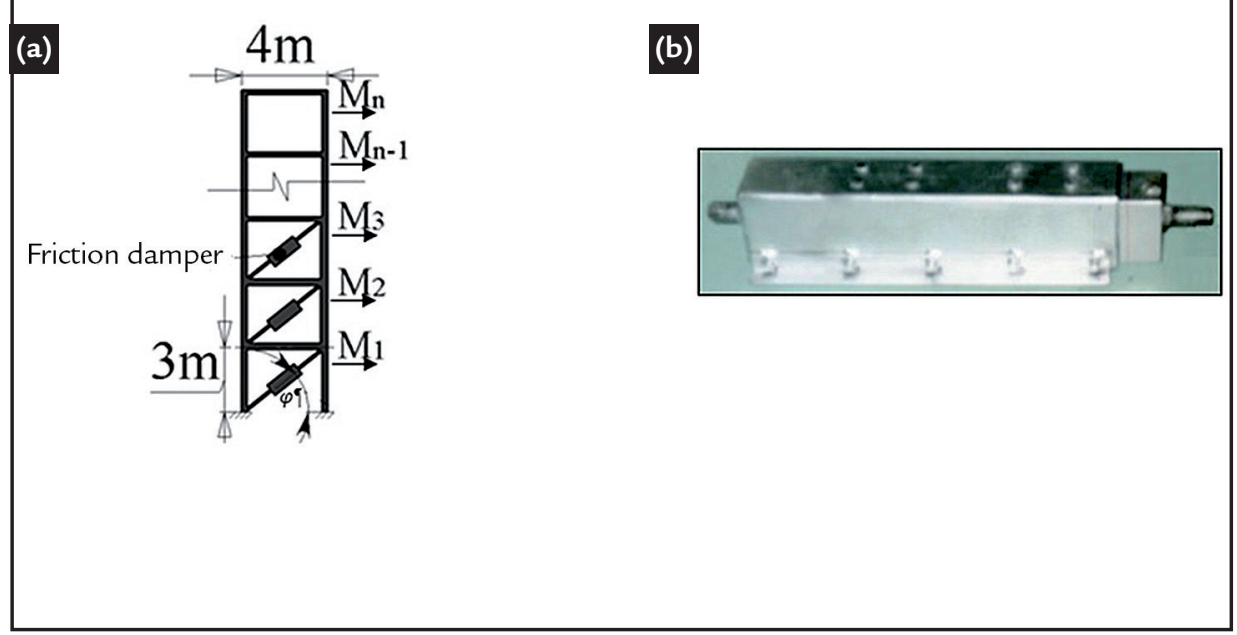

\subsection{Analyzed structures}

A nine-story building and a sixteen-story building, $3 \mathrm{~m}$ high on each floor and $4 \mathrm{~m}$ wide have been simulated. Figure 1(a) shows the diagonal disposition of the friction dampers and the arrows represent the degrees of freedom of each story for both structures. The properties of each structure are presented in Table 1.

Initially, the natural frequencies of the structures were determined, which are important parameters to determine the integration step $\Delta \mathrm{t}=1 \times 10^{-4}$ ) s that must be less than a critical time step to
Figure 1

a) $n$-story building with friction dampers.

b) Friction damper Model-A.

guarantee the convergence of the finite differences method. It is noteworthy that the damping ratio assumed for the first and second vibration mode is $0.5 \%$ $(\xi=0.005)$. Table 2 presents the five first natural frequencies of the nine-story and sixteen-story structures. 
Nine-story mass lumped structure properties.

Table 1

Properties of the buildings.

Table 2

First five natural

frequencies of the structures.

In order to illustrate the proposed optimization procedure, two real seismic records were chosen as excitation to the structures analyzed. The first seismic record is the earthquake that occurred in Caucete, province of San Juan, Argentina, in 1977

\subsection{Dampers optimization}

In this work, the simultaneous optimization of friction dampers is used with the aim of minimizing three different objective functions (see Table 3): (i) the maximum displacement at the top of the structure $\boldsymbol{D}_{\max }$, (ii) the maximum inter-story drift $\boldsymbol{d}_{\max }$ and (iii) the maximum acceleration at the top of the structure $\boldsymbol{A}_{\max }$. In order to find the best local minima, the authors developed a computational routine using MATLAB, linked with the Firefly Algorithm. The Firefly Algorithm is a metaheuristic algorithm developed by Xin-She Yang, in 2008. If the reader requires more information about the Firefly Algorithm, the authors recommended reading the book Yang (2008). Notably, the optimization problem considered in this paper is complex because there are discrete and continuous design variables at same time. The location of the friction dampers is a discrete design variable, whereas the friction force of each device is best represented by a continuous number; this is a continuous design variable. The constraints are the number of available

\begin{tabular}{c|c|c}
\hline Story (i) & Mass $\left(\mathrm{m}_{\mathrm{i}}\right)$ in $\mathrm{kg}$ & Stiffness $\left(\mathrm{k}_{\mathrm{i}}\right)$ in N/m \\
\hline 1 to 2 & 103017.33 & $9.89 \mathrm{E} 8$ \\
\hline 3 to 6 & 103017.33 & $7.90 \mathrm{E} 8$ \\
\hline 7 & 103017.33 & $4.04 \mathrm{E} 8$ \\
\hline 8 & 103017.33 & $2.89 \mathrm{E} 8$ \\
\hline 9 & 103017.33 & $1.85 \mathrm{E} 8$ \\
\hline Story $(\mathrm{i})$ & Sixteen-story mass lumped structure properties \\
\hline 1 & Mass $\left(\mathrm{m}_{\mathrm{i}}\right)$ in kg & Stiffness $\left(\mathrm{k}_{\mathrm{i}}\right) \mathrm{em} \mathrm{N} / \mathrm{m}$ \\
\hline 2 to 13 & 68530 & $2.56 \mathrm{E} 9$ \\
\hline 14 to 16 & 57940 & $2.56 \mathrm{E} 9$ \\
\hline
\end{tabular}

\begin{tabular}{c|c|c|c|c|c} 
Building & $f 1$ & $f 2$ & $f 3$ & $f 4$ & $f 5$ \\
\hline 9-Story & 2.26 & 5.35 & 8.89 & 11.64 & 14.72 \\
\hline 16-Story & 3.18 & 9.28 & 14.96 & 20.74 & 26.59 \\
\hline
\end{tabular}

and the second is the El Centro earthquake, which occurred in the southeastern California on the boarder of the United States and Mexico in 1940. As known, earthquakes are stochastic in nature and because of that, researchers have been working on develop-

positions for the friction dampers $\left(n_{p}\right)$ and the maximum number of dampers to be installed in the structures $\left(\mathrm{n}_{d}\right)$. In the ninestory building, the maximum number of positions is $n_{p}=9$ (one in each story) and the maximum number of friction dampers to be optimized is $n_{d}=3$. Whereas, in the sixteen-story structure, the maximum number of positions is $n_{p}=16$ and the maximum number of friction dampers is $n_{d}=4$. For the discrete design variables ( $\mathbf{P}$ positions), the lower and upper boundaries highlight stories of the structure. For the continuous design variables (friction forces), the limits adopted for both the nine-story structure and sixteen-story structure are $500 \mathrm{kN} \leq F_{f n} \leq 1500 \mathrm{kN}$ for Caucete earthquake and $1400 \mathrm{kN} \leq \boldsymbol{F}_{f n} \leq 2400 \mathrm{kN}$ for $\mathrm{El}$ Centro earthquake. Due to convenience of notation, design variables are grouped into $\mathbf{y}=\left[\mathbf{P} \boldsymbol{F}_{f n}\right]$.

For purposes of ensuring optimal response, preventing the Firefly Algorithm from converging at local optimum, the fireflies' population was set ing robust optimization methodologies that allow projections for friction dampers that are less sensitive to the uncertainties of these phenomena and it is possible to find some works in literature (e.g., Miguel et al. (2014) and Miguel et al. (2016b)).

at fifty fireflies and the iterations at one thousand. In each iteration, the Firefly Algorithm will analyze fifty objective functions, saving the best objective in each iteration and comparing it with the above until it completes the number of iterations. In terms of computational time, convergence criteria by iteration number present a moderated cost, around five hours using an Intel Core I74700MQ processor. In order to improve the optimization technique, the authors developed other convergence criteria using a counter that counts the iteration number without changing the incumbent (best objective of present iteration) until getting to one hundred (the $10 \%$ of the iterations previously determined, that is, one thousand). Thus, the Firefly Algorithm may converge by either of the two convergence criteria. It is worth highlighting that the convergence criteria developed reduces the computational time, in the best case, up to a third of the time spent by the convergence criteria for number of iterations. 


\begin{tabular}{c|c|c|c|} 
Find & \multicolumn{3}{|c|}{$\boldsymbol{y}$} \\
\hline Minimize & $Z_{1}(\boldsymbol{y})=\boldsymbol{D}_{\max }(\boldsymbol{y})$ & $Z_{2}(\boldsymbol{y})=d_{\max }(\boldsymbol{y})$ & $Z_{3}(\boldsymbol{y})=\boldsymbol{A}_{\max }(\boldsymbol{y})$ \\
\hline Subjected to & \multicolumn{3}{c}{$\begin{array}{c}F_{f n}^{\min } \leq F_{f n}^{j} \leq F_{f n}^{\max }, j=1, \ldots, n_{d} \\
n_{p} \text { (number of available positions) } \\
n_{d} \text { (maximum number of dampers) }\end{array}$} \\
\hline
\end{tabular}

\section{Analyzing results}

The results of the friction damper optimization for each structure subjected to two seismic records are present in this section. Thus, regarding the nine-story building, Table 4 and 5 show that in each objective function (displacement, interstory drift and acceleration) the optimal place for the friction dampers in two independent runs is the same, obtaining a reduction between $69 \%$ and $83 \%$ for both cases of the Caucete and El Centro earth- quakes. In the case of Caucete earthquake, for the displacement and inter-story drift objective functions, the best positions are the three first stories, obtaining reduction over $70 \%$ and for acceleration at the top, the positions have changed, so the second and third damper took a different position; that is, the new positions are close to the middle and in the top of the structure, thus, ensuring better acceleration control. For the case of El Centro earthquake,

Table 3

Objective functions.

for each objective function the positions are different, since El Centro has a peak ground acceleration greater than the Caucete earthquake and possibly excited the second and third vibration mode of the structure. On the other hand, the results show that the structure presents a good performance with three friction dampers when it is subjected to two different seismic records, as is possible to be seen in Figure 2 a), Figure 2 b) and Figure 2 c).

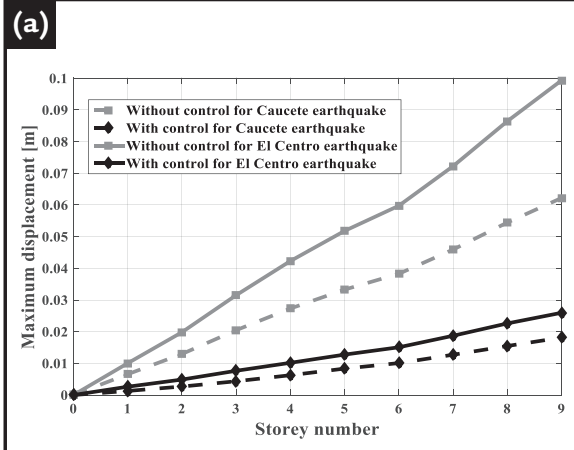

(b)

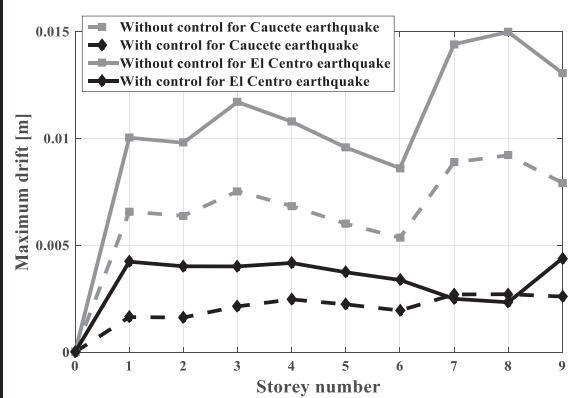

(c)

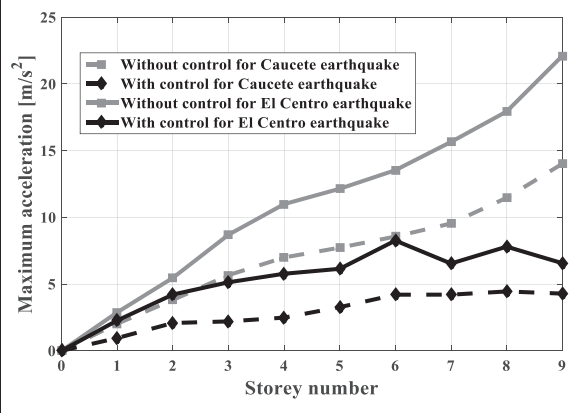

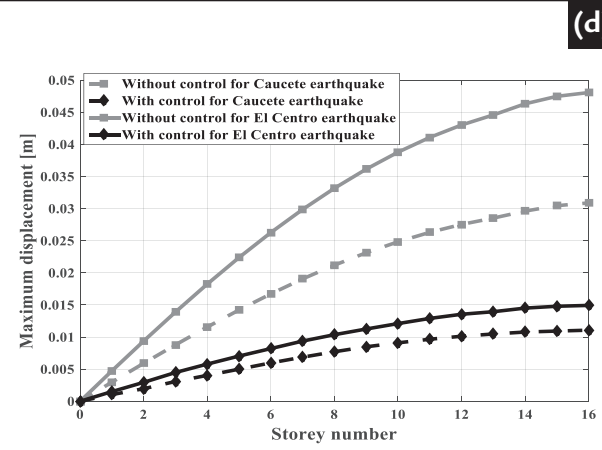

(e)

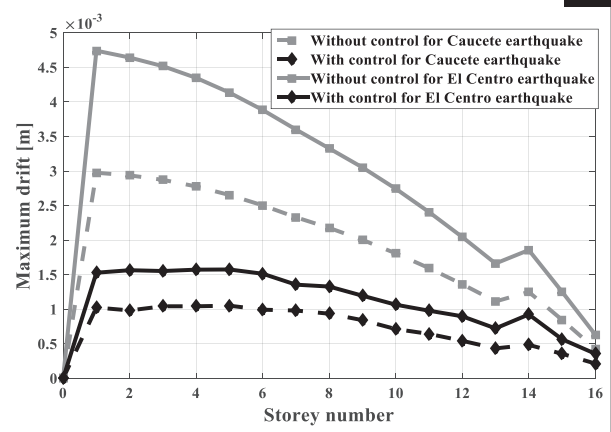

(f)

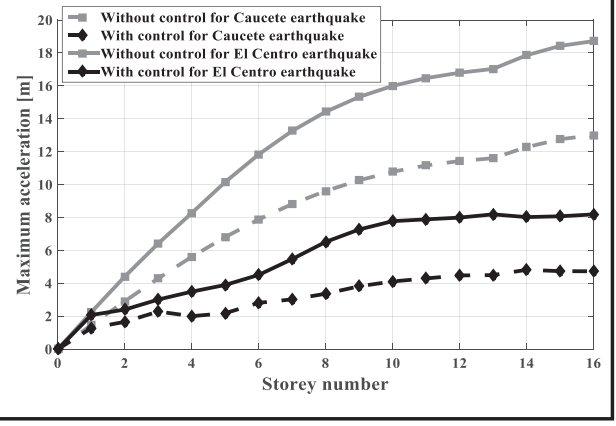

Figure 2

a) Maximum displacement per story for nine-story building.

b) Maximum inter-story drift per story for nine-story building. c) Maximum acceleration per story for nine-story building. d) Maximum displacement per story for sixteen-story building. e) Maximum inter-story drift per story for sixteen-story building. f) Maximum acceleration per story for sixteen-story building. 
Table 4

Optimal force and placement of friction dampers for nine-story structure subjected to Caucete earthquake.

Table 5

Optimal force and placement of friction dampers for nine-story structure subjected to El Centro earthquake.

On the other hand, concerning a sixteen-story building, Tables 6 and 7 show that for each objective function, the optimal place for the friction dampers

Table 6

Optimal force and placement of friction dampers for sixteen-story structure subjected to Caucete earthquake.

\begin{tabular}{c|c|c|c} 
Run & Best positions & Best friction forces $\boldsymbol{F}_{f n}(\mathrm{kN})$ & Displacement $(\mathrm{m})$ \\
\hline- & Without dampers & Uncontrolled structure & 0.0622 \\
\hline 1 & {$[123]$} & {$[1273.044 ; 1214.644 ; 1020.132]$} & 0.0181 \\
\hline 2 & {$[123]$} & {$[1059.405 ; 1220.722 ; 1109.620]$} & 0.0185 \\
\hline Run & Best positions & Best friction forces $\boldsymbol{F}_{f n}(\mathrm{kN})$ & Drift $(\mathrm{m})$ \\
\hline- & Without dampers & Uncontrolled structure & 0.0092 \\
\hline 1 & {$[123]$} & {$[1084.077 ; 967.932 ; 805.701]$} & 0.0027 \\
\hline 2 & {$[123]$} & {$[1127.743 ; 948.712 ; 801.113]$} & 0.0028 \\
\hline Run & Best positions & Best friction forces $\boldsymbol{F}_{f n}(\mathrm{kN})$ & Acceleration $\left(\mathrm{m} / \mathrm{s}^{2}\right)$ \\
\hline- & Without dampers & Uncontrolled structure & 14.01 \\
\hline 1 & {$[139]$} & {$[856.542 ; 734.342 ; 863.966]$} & 4.28 \\
\hline 2 & {$[139]$} & {$[864.307 ; 674.955 ; 837.819]$} & 4.31 \\
\hline
\end{tabular}

\begin{tabular}{c|c|c|c} 
Run & Best positions & Best friction forces $\boldsymbol{F}_{f n}(\mathrm{kN})$ & Displacement $(\mathrm{m})$ \\
\hline- & Without dampers & Uncontrolled structure & 0.0933 \\
\hline 1 & {$[123]$} & {$[2160.424 ; 2089.633 ; 1830.430]$} & 0.0260 \\
\hline 2 & {$[123]$} & {$[2078.582 ; 1940.228 ; 2066.052]$} & 0.0260 \\
\hline Run & Best positions & Best friction forces $\boldsymbol{F}_{f n}(\mathrm{kN})$ & Drift $(\mathrm{m})$ \\
\hline- & Without dampers & Uncontrolled structure & 0.0150 \\
\hline 1 & {$[37$ 8] } & {$[1832.105 ; 1625.966 ; 1935.730]$} & 0.0023 \\
\hline 2 & {$[37$ 8] } & {$[1894.825 ; 1538.676 ; 1832.540]$} & 0.0025 \\
\hline Run & Best positions & Best friction forces $F_{-}$fn $(\mathrm{kN})$ & Acceleration $\left(\mathrm{m} / \mathrm{s}^{2}\right)$ \\
\hline- & Without dampers & Uncontrolled structure & 22.1 \\
\hline 1 & {$[7$ 8 9] } & {$[2003.339 ; 1409.853 ; 1901.196]$} & 6.57 \\
\hline 2 & {$[7$ 8 9] } & {$[2155.808 ; 1600.644 ; 1812.571]$} & 6.63 \\
\hline
\end{tabular}

did not change in two independent runs, obtaining a reduction between 54\% and $69 \%$ for both the Caucete earthquake and El Centro earthquake. This optimal results show that the structure presents a good behavior with four friction dampers, as is possible to appreciate in the Figure 2 d), Figure 2 e) and Figure 2 f).

\begin{tabular}{|c|c|c|c|}
\hline Run & Best positions & Best friction forces $F_{f n}(\mathrm{kN})$ & Displacement (m) \\
\hline- & Without dampers & Uncontrolled structure & 0.0309 \\
\hline 1 & {$\left[\begin{array}{llll}1 & 2 & 3 & 4\end{array}\right]$} & {$[1347.064 ; 1261.545 ; 1284.420 ; 977.418]$} & 0.0111 \\
\hline 2 & {$\left[\begin{array}{llll}1 & 2 & 3 & 4\end{array}\right]$} & {$[1435.804 ; 1402.845 ; 934.765 ; 1029.105]$} & 0.0114 \\
\hline Run & Best positions & Best friction forces $\boldsymbol{F}_{f n}(\mathrm{kN})$ & Drift $(m)$ \\
\hline- & Without dampers & Uncontrolled structure & 0.003 \\
\hline 1 & {$\left[\begin{array}{llll}1 & 2 & 3 & 4\end{array}\right]$} & {$[1170.998 ; 1017.468 ; 827.659 ; 653.227]$} & 0.001 \\
\hline 2 & {$\left[\begin{array}{llll}1 & 2 & 3 & 4\end{array}\right]$} & {$[1374.319 ; 1054.604 ; 871.663 ; 744.612]$} & 0.001 \\
\hline Run & Best positions & Best friction forces $F_{f n}(\mathrm{kN})$ & Acceleration $\left(\mathrm{m} / \mathrm{s}^{2}\right)$ \\
\hline- & Without dampers & Uncontrolled structure & 13 \\
\hline 1 & {$\left[\begin{array}{llll}1 & 2 & 3 & 4\end{array}\right]$} & [1268.854; 1101.253; 1245.189; 911.714] & 4.73 \\
\hline 2 & {$\left[\begin{array}{llll}1 & 2 & 3 & 4\end{array}\right]$} & [1328.322; 1197.209; 1063.332; 967.793] & 4.78 \\
\hline
\end{tabular}




\begin{tabular}{|c|c|c|c|}
\hline Run & Best positions & Best friction forces $F_{f n}(\mathrm{kN})$ & Displacement (m) \\
\hline- & Without dampers & Uncontrolled structure & 0.0481 \\
\hline 1 & {$\left[\begin{array}{llll}1 & 2 & 3 & 4\end{array}\right]$} & {$[2273.058 ; 2017.112 ; 1684.062 ; 1781.484]$} & 0.0149 \\
\hline 2 & {$\left[\begin{array}{llll}1 & 2 & 3 & 4\end{array}\right]$} & {$[2289.553 ; 2207.992 ; 2062.549 ; 1738.898]$} & 0.0155 \\
\hline Run & Best positions & Best friction forces $F_{f n}(\mathrm{kN})$ & Drift $(m)$ \\
\hline- & Without dampers & Uncontrolled structure & 0.0047 \\
\hline 1 & {$\left[\begin{array}{llll}1 & 2 & 3 & 4\end{array}\right]$} & {$[2326.140 ; 1959.337 ; 1970.104 ; 1806.928]$} & 0.0015 \\
\hline 2 & {$\left[\begin{array}{llll}1 & 2 & 3 & 4\end{array}\right]$} & [1765.789; 1791.773; 1726.467; 1711.397] & 0.0016 \\
\hline Run & Best positions & Best friction forces $F_{f n}(\mathrm{kN})$ & Acceleration $\left(\mathrm{m} / \mathrm{s}^{2}\right)$ \\
\hline- & Without dampers & Uncontrolled structure & 18.72 \\
\hline 1 & {$\left[\begin{array}{llll}1 & 2 & 3 & 4\end{array}\right]$} & {$[2109.650 ; 2013.593 ; 1902.379 ; 1628.848]$} & 8.19 \\
\hline 2 & {$\left[\begin{array}{llll}1 & 2 & 3 & 4\end{array}\right]$} & [1861.356; 1814.622; 1539.999; 1795.197] & 8.65 \\
\hline
\end{tabular}

\section{Conclusions}

Damper optimization using metaheuristic algorithms is a relatively new area, and today is one of the most explored fields of knowledge because there is the need to confront new challenges for designing safer, economically feasible structures in locations with high seismic activity. Thus, this paper proposed an optimization methodology for optimum use of friction dampers. It is noteworthy that the optimization of this sort of damper (friction damper) is a relatively unexplored subject in the world, which proves the innovative character of this paper.

Through the numerical simulations presented, it was concluded that in all cases studied the proposed methodology proved to be very effective in reducing the dynamic response, reaching reductions of over $70 \%$, and in a worst case scenario, reached reductions in the or-
Table 7

Optimal force and placement

of friction dampers for sixteen-story structure subjected to El Centro earthquake.

\section{Acknowledgments}

der of $54 \%$. It is noteworthy that these reductions have been achieved with a limited number of friction dampers due to the fact that these dampers have been optimized, i.e., they are positioned in places where they dissipate more energy and their capacities (frictional forces) are also optimal.

Finally, this study showed that it is possible to design friction dampers through an economical and effective way.

The authors acknowledge the financial support of CNPq and CAPES.

\section{References}

FANG, J., WANG, Q., WANG, S., WANG, Q. Min-max criterion to the optimal design of vibration absorber in a system with Coulomb friction and viscous damping. Nonlinear Dynamics, v. 70, p. 393-400, 2012.

MIGUEL, L. F. F. Estudo teórico e experimental de amortecedores de vibração por atrito. Brasil: Programa de Pós-Graduação em Engenharia Civil, Laboratório de Dinâmica Estrutural e Confiabilidade, UFRGS, 2002. (Master Dissertation).

MIGUEL, L.F.F., RIERA, J.D. Controle de vibrações de estruturas utilizando amortecedores por atrito. Revista Internacional de Desastres Naturales, Accidentes e Infraestructura Civil, v. 8, n. 1, p. 57-70, 2008.

MIGUEL, L. F. F., FADEL MIGUEL, L. F. Shape and size optimization of truss structures considering dynamic constraints through modern metaheuristic algorithms. Expert Systems with Applications, 39, p. 9458-9467, 2012.

MIGUEL, L.F.F., LOPEZ, R.H., MIGUEL, L.F.F. Multimodal size, shape, and topology optimisation of truss structures using the Firefly algorithm. Advances in Engineering Software, v. 56, p. 23-37, 2013.

MIGUEL, L.F.F., MIGUEL, L.F.F., LOPEZ, R.H. Robust design optimization of friction dampers for structural response control. Structural Control and Health Monitoring, v. 21, n. 9, p. 1240-1251, 2014.

MIGUEL, L. F. F., FADEL MIGUEL, L. F., LOPEZ, R. H. A firefly algorithm for the design of force placement of friction dampers for control of main-induced vibrations in footbridges. Optimization Engineering, v. 16, p. 633-661, 2015.

MIGUEL, L. F. F., FADEL MIGUEL, L. F., AND LOPEZ, R. H. Simultaneous opti- 
mization of force and placement of friction dampers under seismic loading. Engineering Optimization, v.48, n.4, p. 582-602, doi:10.1080/0305215X.2015.1025774

MIGUEL, L. F. F., FADEL MIGUEL, L. F., AND LOPEZ, R. H. Failure probability minimization of buildings through passive friction dampers. The Structural Design of Tall and Special Buildings, Online, 2016b. doi: 10.1002/tal.1287

MOSTAGHEL, N., DAVIS, T. Representations of Coulomb friction for dynamic analysis. Earthquake Engineering and Structural Dynamics, v. 26, n. 5, p.541-548, 1997.

ONTIVEROS-PÉREZ, S. P. Otimização simultânea de posições e forças de amortecedores de vibração por atrito para controle de vibrações de estruturas. Brazil: PROMEC/UFRGS, 2014. (Dissertação de Mestrado).

SOONG, T.T., DARGUSH, G.F. Passive energy dissipation system in structural engineering. Chichester, U.K., Wiley, 1997.

TAKEWAKI, I., TSUJI, M., YOSHITOMI, S., ADACHI, F. Nonlinear optimal oil damper design in seismically controlled muli-story building frame. Soil Dynamic and Earthquake Engineering, v. 44, p.1-13, 2013.

YANG, XS. Nature-inspired metaheuristic algorithms. United Kingdom: Luniver Press, 2008, 116 p.

Received: 27 April 2015 - Accepted: 21 March 2017. 